\title{
A new oxidation flow reactor for measuring secondary aerosol formation of rapidly changing emission sources
}

Pauli Simonen et al.

Correspondence to: Pauli Simonen (pauli.simonen@tut.fi)

The copyright of individual parts of the supplement might differ from the CC-BY 3.0 licence. 
The PAM OH exposure as a function of ozone concentration measured after the PAM is presented in Fig. S1. The OH exposure was determined by measuring the $\mathrm{SO}_{2}$ loss as in Sect. 2.4, and the different ozone concentrations are achieved by varying the lamp voltage.

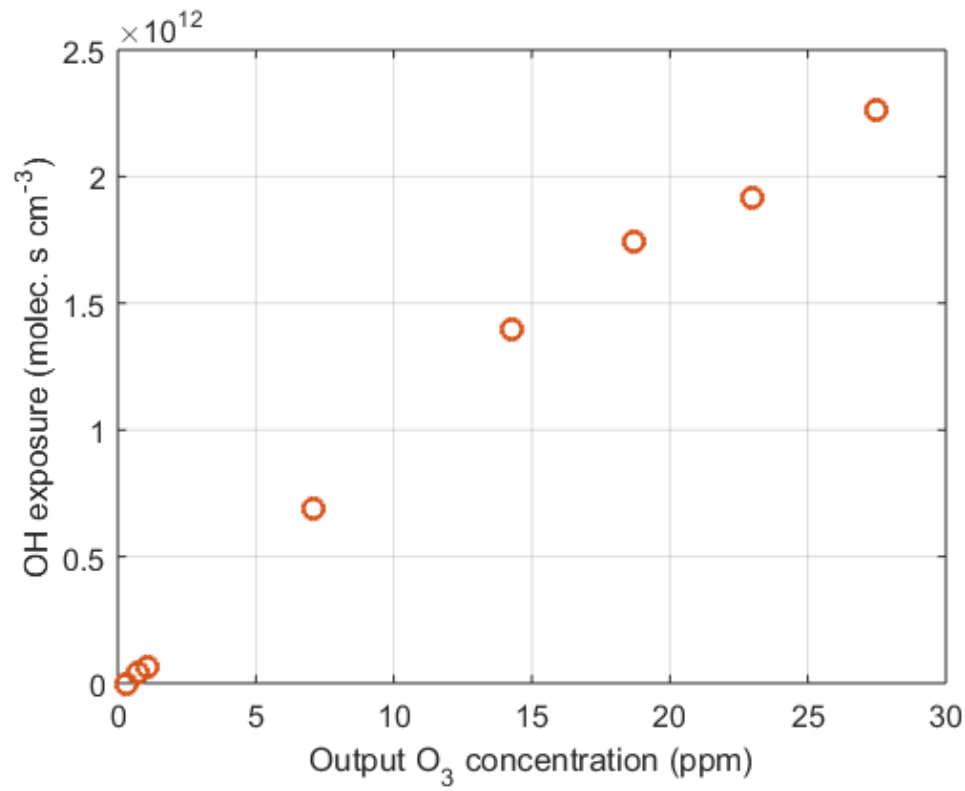

5 Figure S1. PAM OH exposure as a function of output ozone concentration at relative humidity of $27-29 \%$.

Figure S2 shows the sampling setup for engine exhaust measurements. The primary dilution ratio is adjusted by the amount of dilution air for the porous tube diluter and by the flow rate to the vacuum after the residence time chamber. 

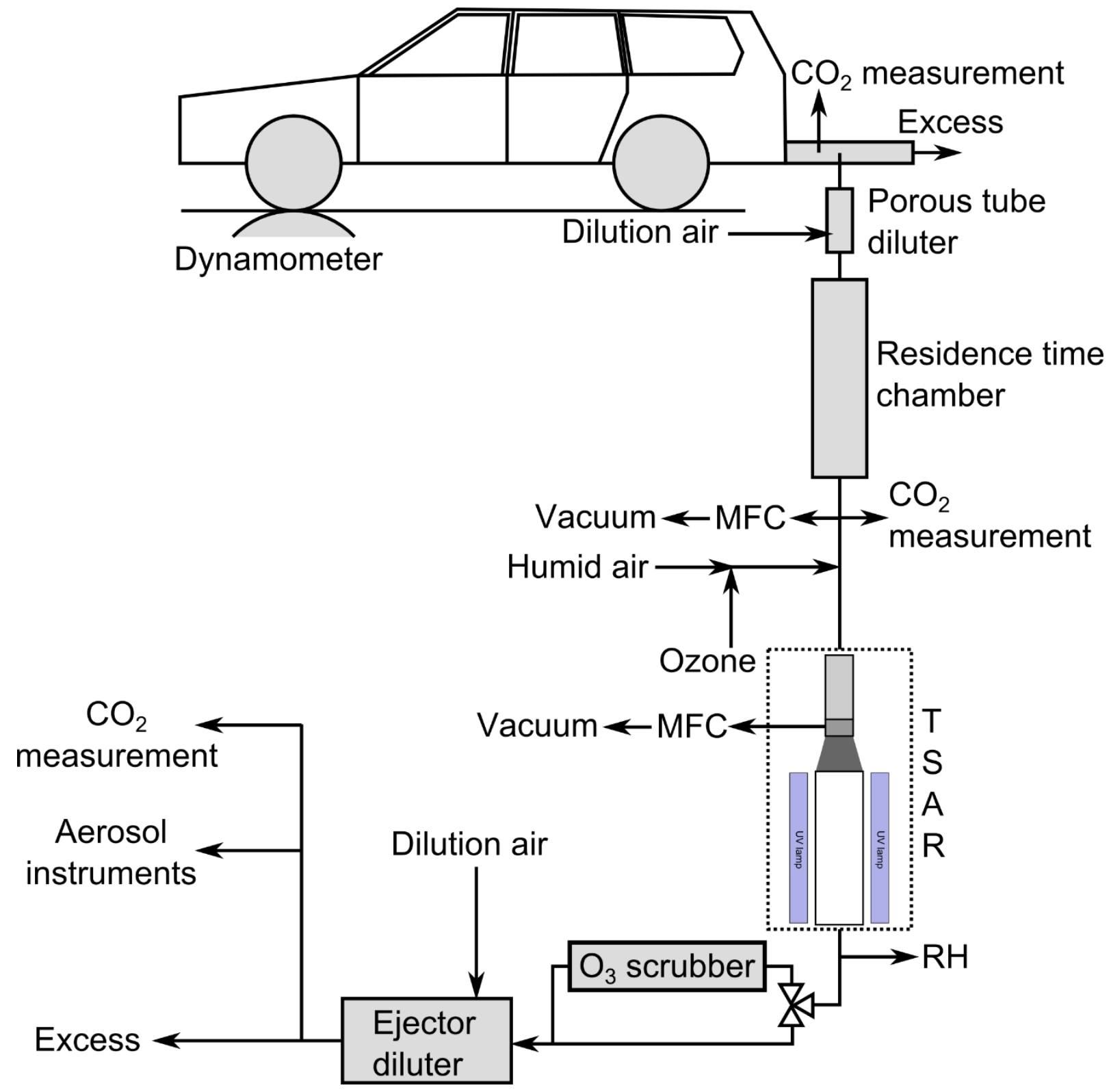

Figure S2. Engine exhaust sampling setup. 


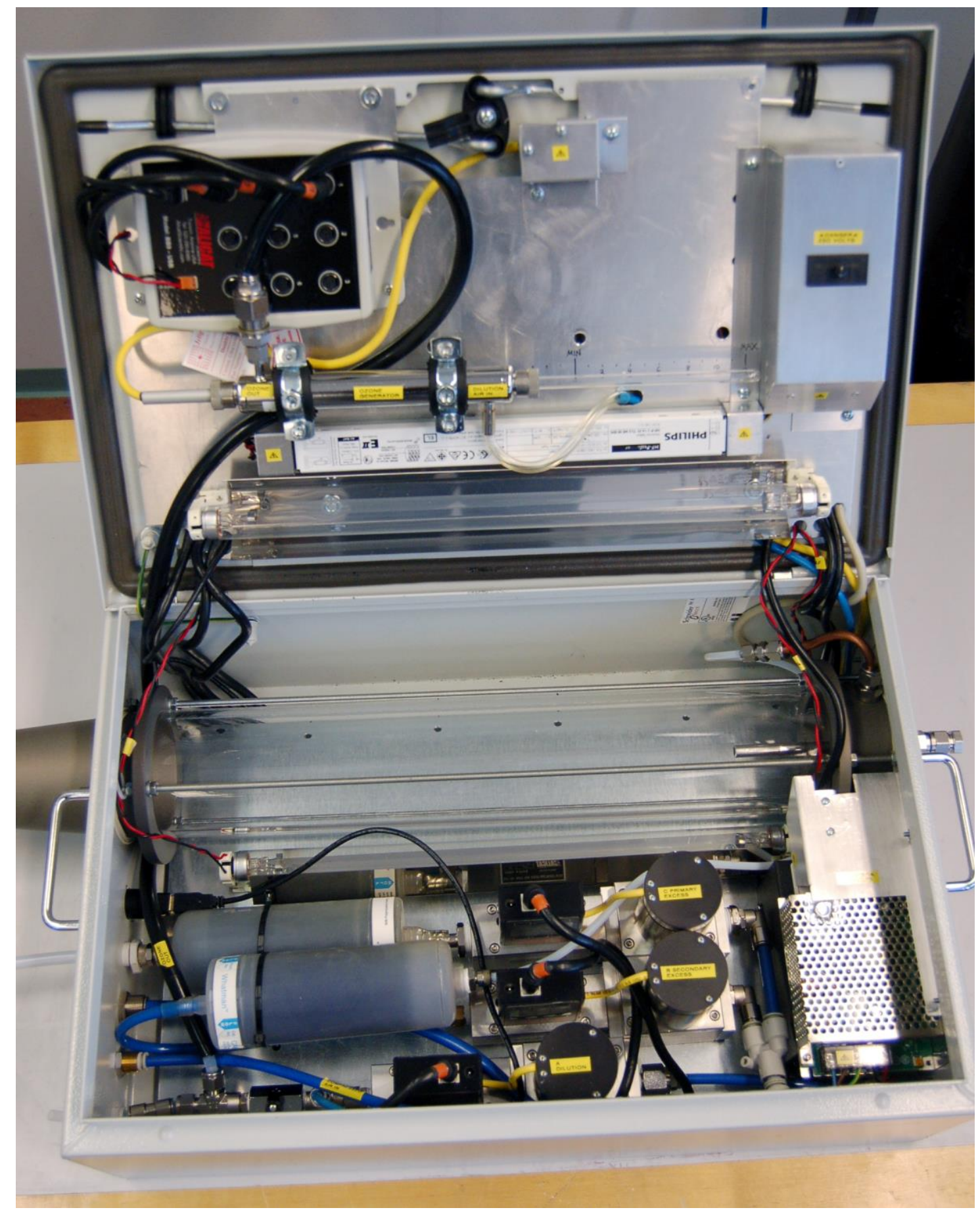

Figure S3. A photograph of TSAR 

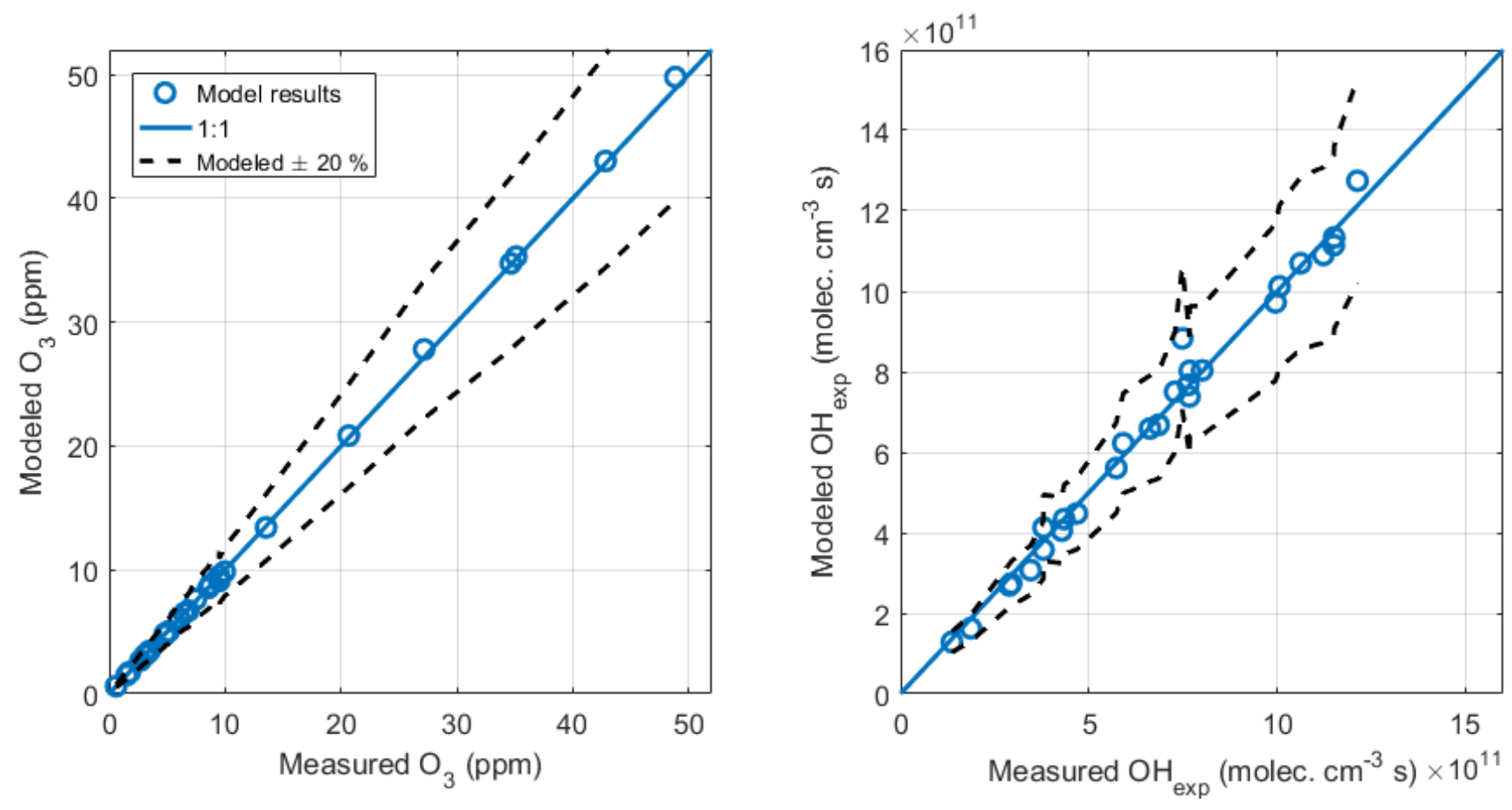

Figure S4. The measured and modeled ozone concentration after TSAR, and the measured and modeled OH exposure for the measurements done in Sect. 3.3.
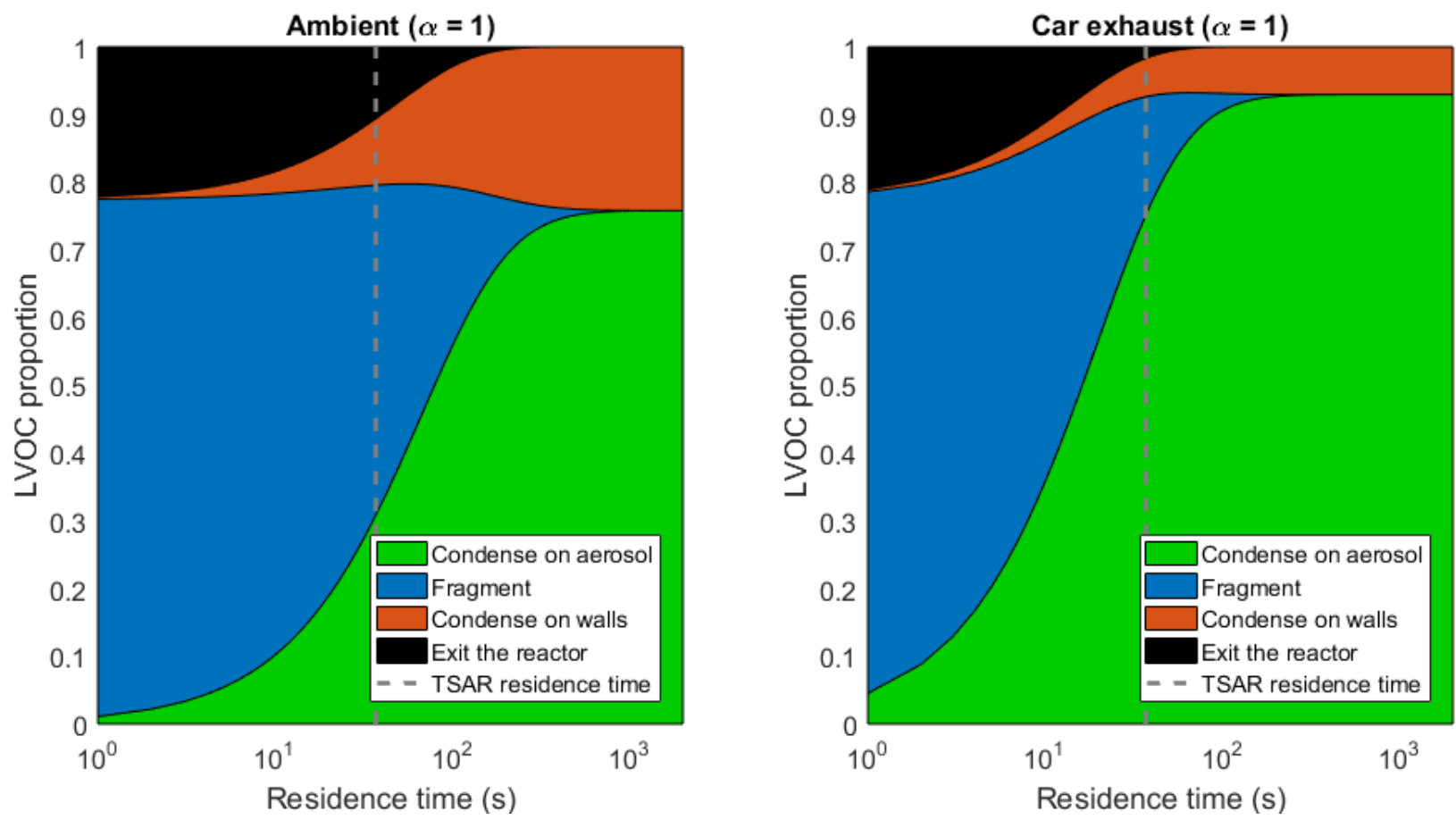

5 Figure S5. The fate of LVOC as a function of residence time for the ambient and the car exhaust case. 


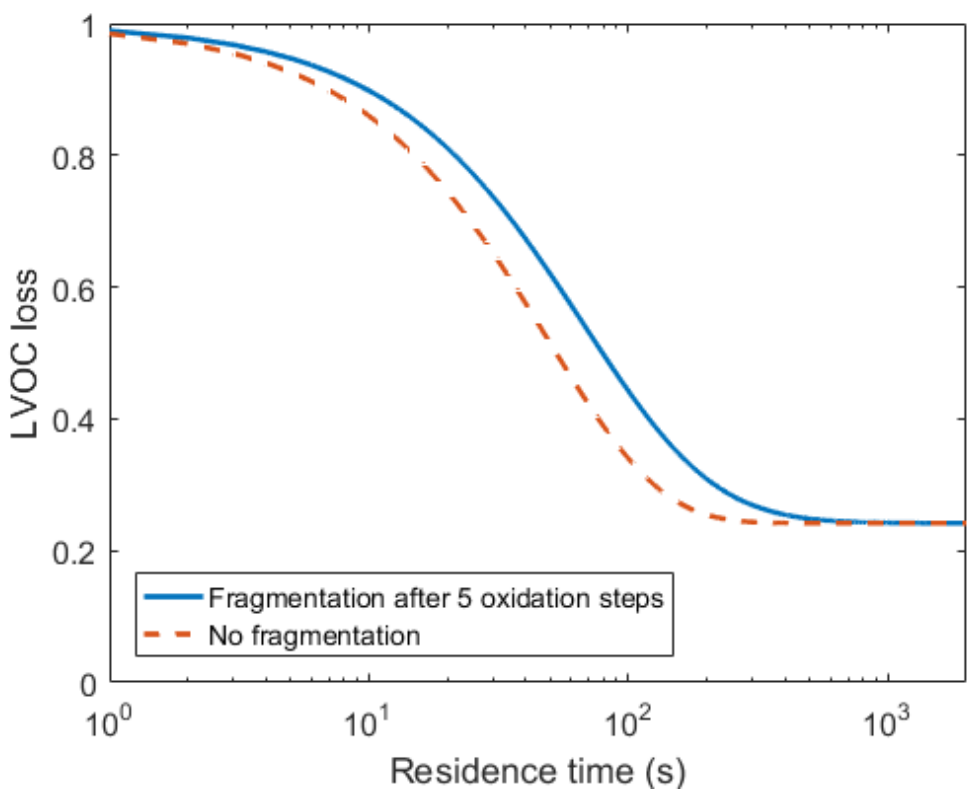

Figure S6. The sensitivity of fragmentation parameter in LVOC loss model for the ambient case. If no fragmentation occurs, the losses are slightly lower at residence times between 10-300 $\mathrm{s}$.
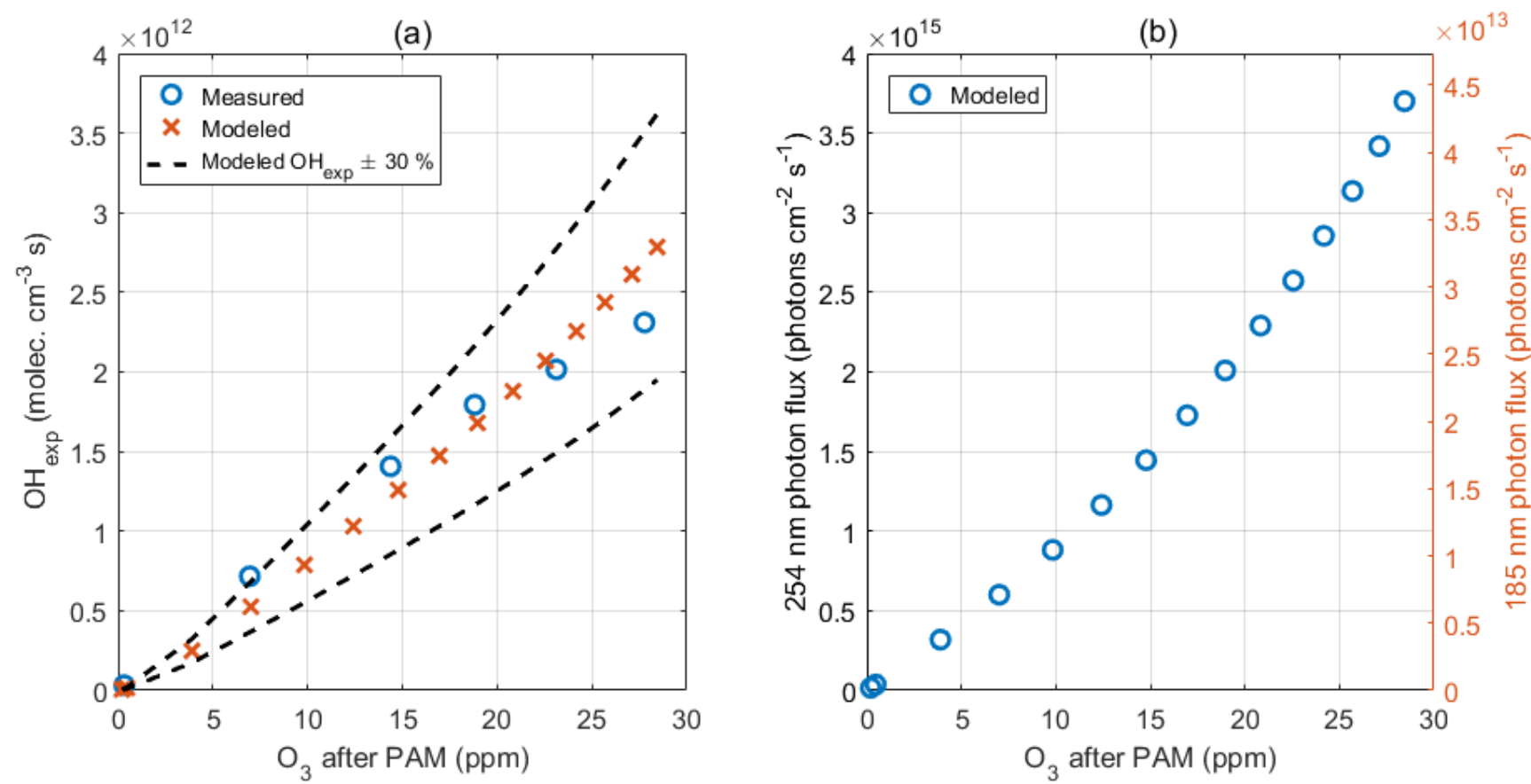

5 Figure S7. Comparison of model and measurement results of PAM OH exposure characterization (a), and the modeled photon flux as a function of modeled ozone concentration after PAM (b). The results were obtained by assuming $\mathrm{OH}$ wall loss coefficient of 8.3 $\mathrm{s}^{-1}$, ozone wall loss coefficient of $7.5 \times 10^{-4} \mathrm{~s}^{-1}$ and that the $185 \mathrm{~nm}$ photon flux is $1.28 \%$ of $254 \mathrm{~nm}$ photon flux. The input parameters were relative humidity, temperature, the initial $\mathrm{SO}_{2}$ concentration and the $254 \mathrm{~nm}$ photon flux.

\section{Calculation of CS and $\mathrm{k}_{\mathrm{w}}$ in LVOC loss model}

10 The condensational sink for a discrete particle size distribution is defined as

$$
C S=\sum_{i} \beta\left(r_{i}\right) r_{i} N_{i},
$$

where $r_{i}$ is the radius of particles in the $i$ th size bin, $N_{i}$ is the number concentration of particles and $\beta$ is the transitional correction factor.

$$
\beta=\frac{K n+1}{0.377 K n+1+\frac{4}{3 \alpha} K n^{2}+\frac{4}{3 \alpha} K n},
$$


where $\alpha$ is the accommodation coefficient of condensing vapor. $K n$ is the Knudsen number.

$$
K n=3 \sqrt{\frac{\pi m}{8 k T}} \frac{D}{r}
$$

where $m$ is the molecular mass and $D$ is the diffusion coefficient of the condensing vapor. (Pirjola et al., 1999)

5 The first-order wall loss rate coefficient is calculated with equation

$k_{w}=\frac{2 A}{\pi V} \sqrt{k_{e} D}$,

where $\mathrm{A}$ is the reactor surface area, $\mathrm{V}$ is the volume of the reactor, $\mathrm{D}$ is the diffusion coefficient of the condensing compound and $k_{e}$ is the coefficient of eddy diffusion. (Palm et al., 2016) The reactor volume dependent value of $k_{e}$ is calculated as in (Krechmer et al., 2016):

$$
k_{e}=0.004+\left(5.6 \times 10^{-3}\right) \cdot V^{0.74}
$$

\section{References}

Krechmer, J. E., Pagonis, D., Ziemann, P. J. and Jimenez, J. L.: Quantification of Gas-Wall Partitioning in Teflon Environmental Chambers Using Rapid Bursts of Low-Volatility Oxidized Species Generated in Situ, Environ. Sci. Technol., 50(11), 5757-5765, doi:10.1021/acs.est.6b00606, 2016.

Palm, B. B., Campuzano-Jost, P., Ortega, A. M., Day, D. A., Kaser, L., Jud, W., Karl, T., Hansel, A., Hunter, J. F., Cross, E. S., Kroll, J. H., Peng, Z., Brune, W. H. and Jimenez, J. L.: In situ secondary organic aerosol formation from ambient pine forest air using an oxidation flow reactor, Atmos. Chem. Phys., 16(5), 2943-2970, doi:10.5194/acp-16-29432016, 2016.

20 Pirjola, L., Kulmala, M., Wilck, R. M., S, S. A. B., S, F. S. and A, E. O.: Formation of Sulphuric Acid Aerosols and Cloud Condensation Nuclei : an Expression for Significant Nucleation and Model Comparison, , 30(8), 1079-1094, 1999. 